\title{
Spatial Limit of CFD Model at Nanometer Scale Geometry: Part I: Capillary Flow
}

\author{
Simon Mark and Harry Boyer
}

\begin{abstract}
Numerical simulation using computational fluid dynamics has been studied broadly in various fields of applications. Along with the advancement in new technology especially those employing micro or nanoscale geometries or lab-on-chip devices, it is important to understand the efficiency of such numerical models at small geometrical scales. To access any potential error in numerical simulation using CFD, in the present work we report the investigation of capillary driven passive flow inside a channel of varying geometry. The potential error in the results of simulation at a very small scale is accessed by comparing it with the results of theoretical analysis. Hence, establishes a spatial limit of the continuum model for simulation in related applications. This gives new insight to the further study on CFD at nanometers scale geometry.
\end{abstract}

\section{Index Terms-CFD, Nanometer Scale, Capillary Flow.}

\section{INTRODUCTION}

Computational Fluid Dynamics (CFD) has been extensively utilized tool in the field of fluid flow and heat transfer. The numerical solution obtained from CFD is based on solving the discretized form of the governing equations which can be compared with the experimental/theoretical results for validation. Along with the advancement in the numerical investigation of capillary flows [1-3] or heat transfer [4-7] in a multiphase system [8-13], it is crucial to investigate the proficiency of utilized CFD tools at small scales. The solution obtained from CFD based on the continuum hypothesis at a very small scale (nanometers scale) is always debatable. Henceforth, in the present research, we investigate the possible error in numerical solution as the scale of geometry narrows down to a few nanometers. For this, we have chosen to study the capillary flow of liquid inside channels of varying height. Liquid flow in channels (mini channels [14-16], microchannels [8, 1718], or nanochannels [19-23]) have been extensively studied in the varying field of applications. Thus, the flow of liquid inside channels can be taken as a benchmark for understanding any new phenomena.

Thus, the ongoing work presents the numerical simulation of capillary flow in channels. The height of the channel is varied from a millimeter to a few nanometers and the effect of the same is studied by comparing it with the theoretical prediction.

Published on July 31, 2020

S. Mark, University of Bridgeport, USA.

(e-mail: marksimon413@gmail.com)

H. Boyer, University of Bridgeport, USA.

\section{NUMERICAL STUDY}

\section{A. Capillary Driven Flow}

When liquid propagates inside a bounded wall geometry of very narrow thickness, the motion is governed by primarily surface tension and wall adhesion. Thus, the flow is directly related to capillary pressure acting at the meniscus and thus capillary driven flow. At the smaller scales, capillary pressure gets dominant and the investigation of the same is carried out in the present research to understand the effect of spatial limit on the continuum simulation.

\section{B. Continuum Analysis}

Computational Fluid Dynamics (CFD) simulations are carried out to investigate the capillary distance evolution with time inside a channel. Finite volume methods are used to discretize the governing equations of fluid flow and capillary pressure, which is, solved simultaneously using a commercial CFD solver ANSYS Fluent [24]. The equations used are conservative and based on the continuum model which always possesses the spatial limit on a small scale. At very small geometry with a scale comparable to the mean free path of the molecules, the fluid molecules behave in a discrete manner rather than continuum and the solution obtained from CFD will tend to diverge from the theoretical prediction.

\section{Theoretical Prediction}

In the present research, we estimate the capillary distance $\left(L_{c}\right)$ obtained inside the channels of varying height and compare it with the theoretical equation. The theoretical equation used for prediction is the Lucas-Washburn Equation [25-26]. The L-W Equation is as follow:

$$
L_{c}=\sqrt{\frac{\gamma h t \cos \theta}{3 \eta}}
$$

Where, $\gamma, h$, and $\eta$ are surface tension, the height of channel and viscosity of the liquid, $\theta$ is the contact angle between the liquid and solid wall $\left(\theta=30^{\circ}\right)$ and $t$ is time.

\section{CFD SimULATIONS}

In this section details in CFD simulations are reported. First, the computational domain utilized is discussed followed by the the results of grid-independence test performed to achieve a converged result.

\section{A. Computational Domain}

Fig. 1 shows the details of the computational domain. A 
channel with specified width (W) and Height $(\mathrm{H})$ is connected to a reservoir (ABCD-A'B'C'D') of relatively very large size. ' $\mathrm{L}$ ' designates the length of the channel while the width ' $\mathrm{W}$ ' and height ' $\mathrm{H}$ ' is shown in the magnified version in Fig. 1. The computational domain is such that, it is symmetric along the $\mathrm{XY}$ plane as well as $\mathrm{XZ}$ plane which offers the reduced computational time.

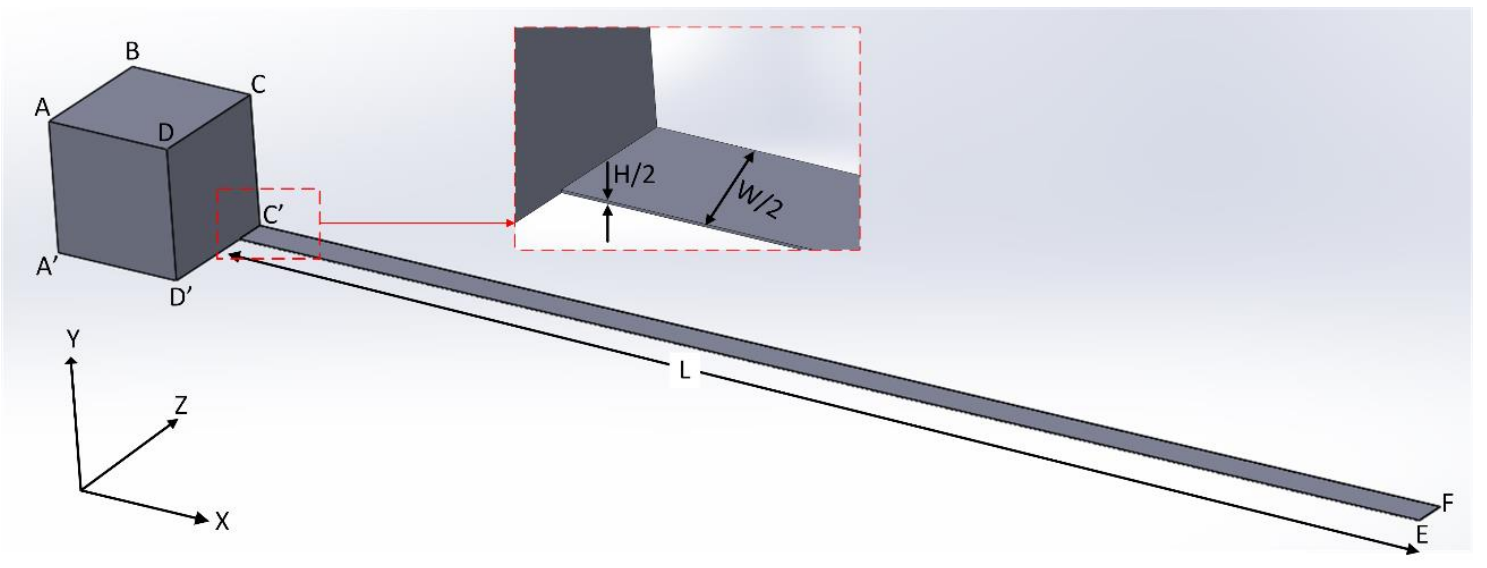

Fig. 1. Details of Computational Domain

\section{B. Grid Independence Test}

(a)

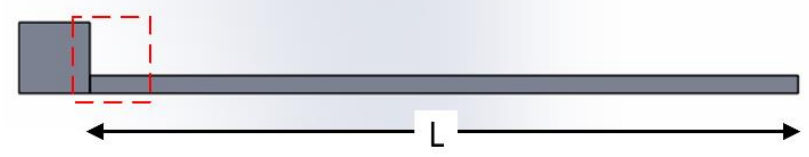

(b)

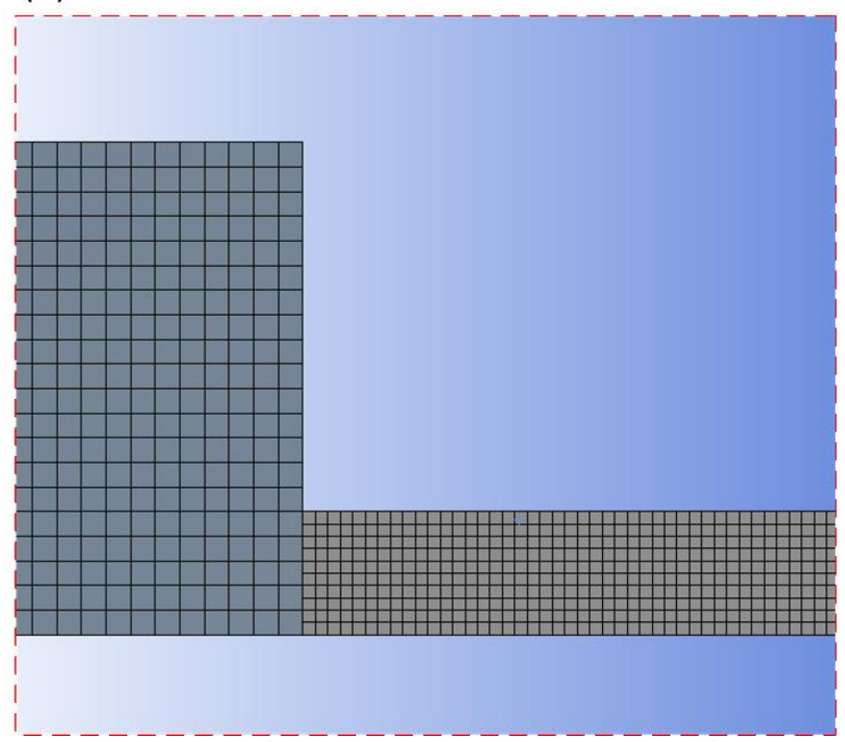

Fig. 2. ( $\bar{a}) \bar{T} \bar{p}$ view of the computational domain (b) Mesh refinement at the channels.

Fig. 2 shows the computational domain along with a part of it that elucidates the mesh generated at the reservoir and channels part. Based on the different grid-spacing parameters, a grid-independence test is carried out.

Accordingly, to have a grid-independent solution, we considered 8 different meshing parameters to obtain corresponding mesh and performed analysis on each as shown in Table I.
TABLE I: THE GRID SIZE OF DIFFERENT MESH

\begin{tabular}{lll}
\hline \hline Grid & No. of Cells & Avg. Element Size \\
\hline Grid 1 & 300 & $1 \mathrm{~mm}$ \\
Grid 2 & 540 & $0.75 \mathrm{~mm}$ \\
Grid 3 & 1,200 & $0.5 \mathrm{~mm}$ \\
Grid 4 & 3,340 & $0.3 \mathrm{~mm}$ \\
Grid 5 & 7,500 & $0.2 \mathrm{~mm}$ \\
Grid 6 & 30,000 & $0.1 \mathrm{~mm}$ \\
Grid 7 & 120,000 & $50 \mu \mathrm{m}$ \\
Grid 8 & 750,000 & $20 \mu \mathrm{m}$ \\
\hline \hline
\end{tabular}

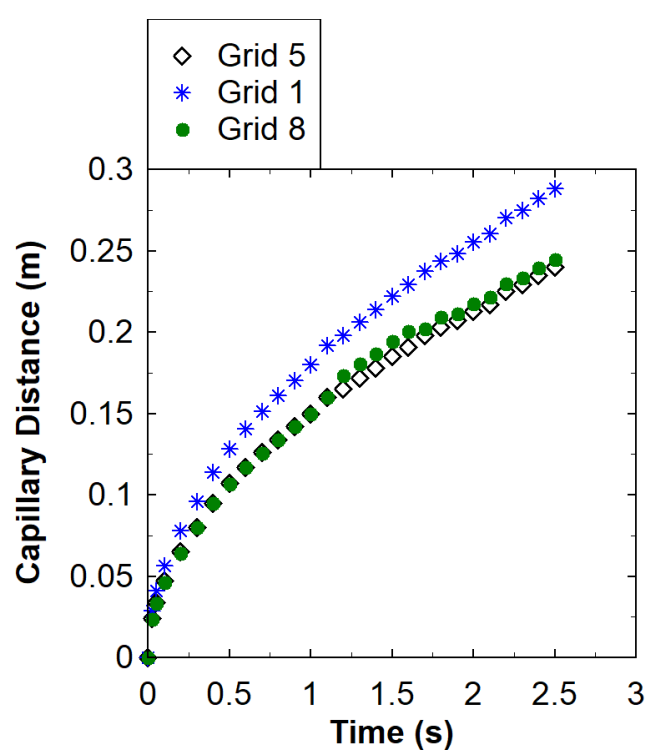

Fig. 3. Variation of capillary distance with time demonstrating the grid independence test.

From the results of different grids, results of capillary distance variation with time are plotted. Fig. 2 shows the variation of capillary distance with time for a case with $\mathrm{H}=$ $1 \mathrm{~mm}, \mathrm{~W}=10 \mathrm{~mm}$ and by considering Grid 1 , Grid 5, and Grid 8 only. Clearly, the results of Grid 5 is consistent with the refined mesh Grid 8. 


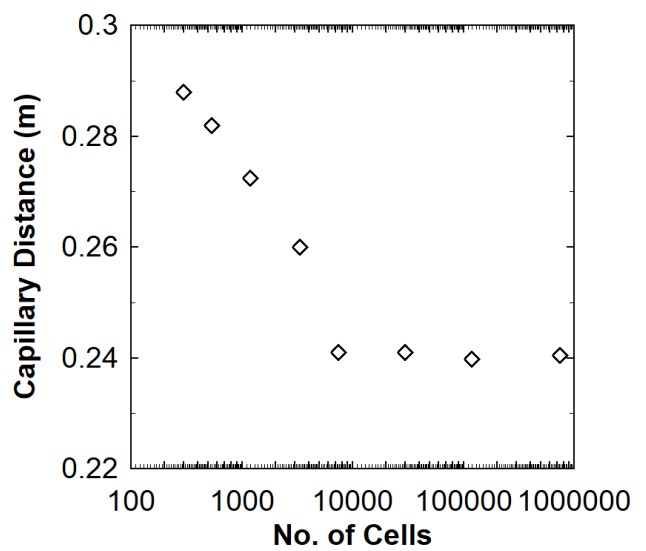

Fig. 4. Variation of capillary distance at time instant $t=2.5 \mathrm{~s}$ obtained at varying number of cells for different grids.

Additionally, Fig. 3 shows the variation of capillary distance $\mathrm{L}_{\mathrm{c}}$ obtained at a particular time instant $\mathrm{t}=2.5 \mathrm{~s}$ by considering all 8 grids of Table I. It is clear from Fig. $2 \& 3$ that the Grid 5 is sufficient to obtain a solution thus, the parameters of Grid 5 is considered as optimum and utilized for all further simulations.

\section{RESUlTS}

As mentioned earlier, the motive of the present research being an investigation of the spatial limit of continuum fluid dynamics using capillary flow, we investigate the capillary flow of liquid in the channels with height $(\mathrm{H})$ varying from $1 \mathrm{~mm}$ to $10 \mathrm{~nm}$. Table II depicts the details of the cases of simulations carried out in the present work.

\begin{tabular}{llll} 
& \multicolumn{3}{c}{ TABLE II: DifFERENT CASES OF Simulations } \\
\hline \hline \multirow{2}{*}{ Case } & Channel & Channel & Channel Length \\
& Height $(\mathrm{H})$ & Width $(\mathrm{W})$ & $(\mathrm{L})$ \\
\hline Case 1 & $1 \mathrm{~mm}$ & $10 \mathrm{~mm}$ & $0.3 \mathrm{~m}$ \\
Case 2 & $100 \mu \mathrm{m}$ & $1 \mathrm{~mm}$ & $0.1 \mathrm{~m}$ \\
Case 3 & $10 \mu \mathrm{m}$ & $1 \mathrm{~mm}$ & $0.04 \mathrm{~m}$ \\
Case 4 & $1 \mu \mathrm{m}$ & $100 \mu \mathrm{m}$ & $0.01 \mathrm{~m}$ \\
Case 5 & $500 \mathrm{~nm}$ & $10 \mu \mathrm{m}$ & $0.01 \mathrm{~m}$ \\
Case 6 & $100 \mathrm{~nm}$ & $10 \mu \mathrm{m}$ & $0.004 \mathrm{~m}$ \\
Case 7 & $50 \mathrm{~nm}$ & $10 \mu \mathrm{m}$ & $0.002 \mathrm{~m}$ \\
Case 8 & $25 \mathrm{~nm}$ & $10 \mu \mathrm{m}$ & $0.0015 \mathrm{~m}$ \\
Case 9 & $10 \mathrm{~nm}$ & $10 \mu \mathrm{m}$ & $0.001 \mathrm{~m}$ \\
\hline \hline
\end{tabular}

For a particular case of simulation, the variation of $\mathrm{L}_{c}$ with time is obtained from the contour plot of volume fraction of liquid as shown in Fig. 5. The results of variation of capillary distance with time for each case of Table II are depicted in Fig. 6. In addition to the results obtained from CFD, we also compute the analytical solution based on the L-W Equation (see Eqn. 1). It is observed that for the smaller channel height both of these don't match well. For the channel height as small as less than $50 \mathrm{~nm}$, this deviation (represented as $\delta$ ) is very significant.

Based on the results as observed, the following reasons are anticipated for the significant variation in the results at a smaller height of the channels;

A. The CFD results are based on the solution of the momentum equation along with capillary pressure. At a very small scale, the pressure inside the channels might alter due to the effect called disjoining pressure [27-28], and the deviation of the result is observed.

$B$. At a very small scale, the geometrical scale is comparable to the mean free path of the molecules, thus, the continuum hypothesis might fail and the CFD results may not return the actual results.

C. In our CFD simulations, we use the material properties of liquid water like density, viscosity, surface tension as a constant value, and equal to the properties at bulk. However, there is evidence [2930] that at small scales the material properties will change, thus CFD results will deviate.

$D$. The grid points/mesh used to compute the numerical results based on CFD might also need more refinement at a smaller scale in order to have results match with the results of the analytical solution.

Thus, we witness that the results of CFD simulations deviate significantly at a very small scale and this is an important observation that is to be taken into consideration for further design and application related to the fluid flow and heat transfer devices especially employing numerical simulations.

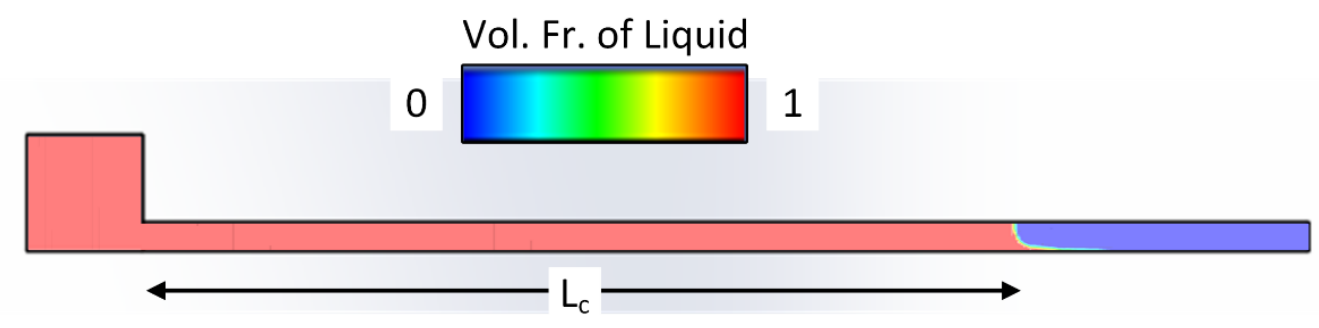

Fig. 5. Volume fraction contour plot of liquid to illustrate the capillary distance $\left(\mathrm{L}_{\mathrm{c}}\right)$

Fig. 7. Reports the variation in deviation percentage with

Additionally, based on the estimation of deviation (d) from the results of Fig. 6, we also plot the percentage in deviation observed as the channel height goes on decreasing. channel height. It is interesting to see that the deviation percentage is very high at such small scales. 
(a) $\mathrm{H}=1 \mathrm{~mm}$

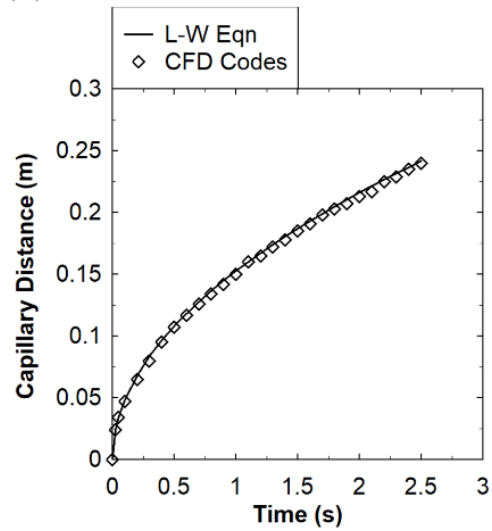

(d) $\mathrm{H}=1 \mu \mathrm{m}$

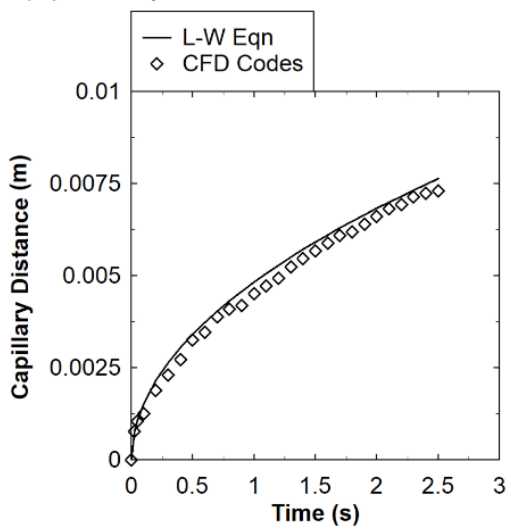

(g) $\mathrm{H}=50 \mathrm{~nm}$

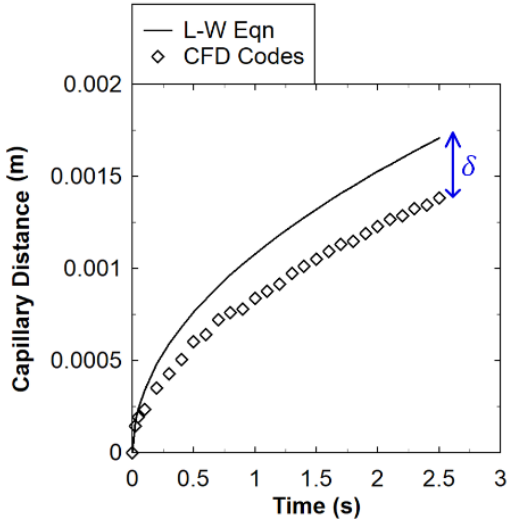

(b) $\mathrm{H}=100 \mu \mathrm{m}$

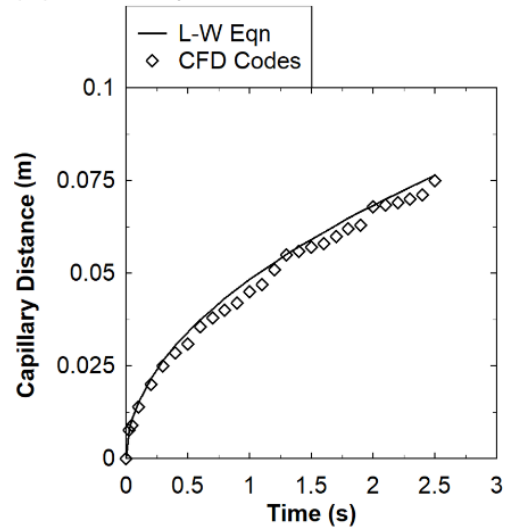

(e) $\mathrm{H}=500 \mathrm{~nm}$

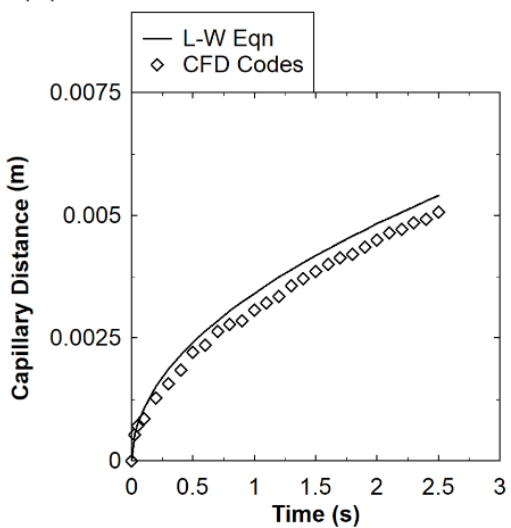

(h) $\mathrm{H}=25 \mathrm{~nm}$

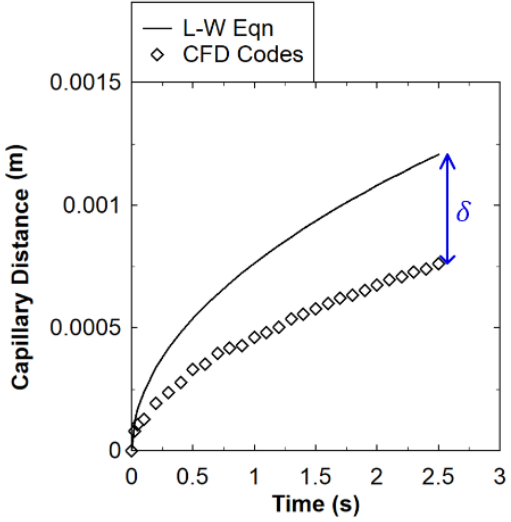

(c) $\mathrm{H}=10 \mu \mathrm{m}$

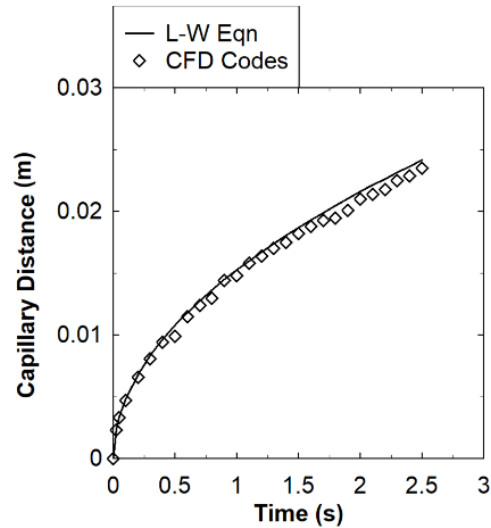

(f) $\mathrm{H}=100 \mathrm{~nm}$

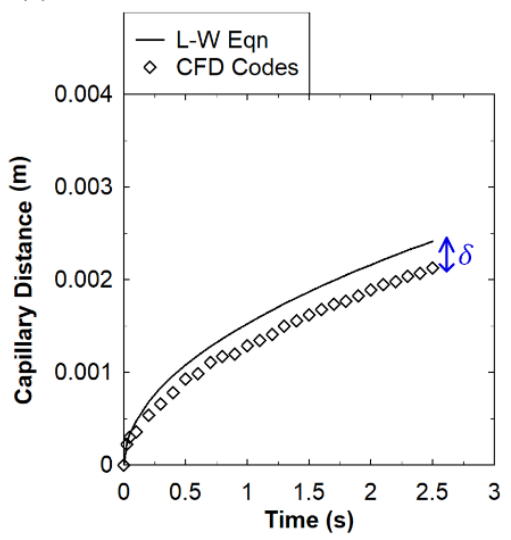

(i) $\mathrm{H}=10 \mathrm{~nm}$

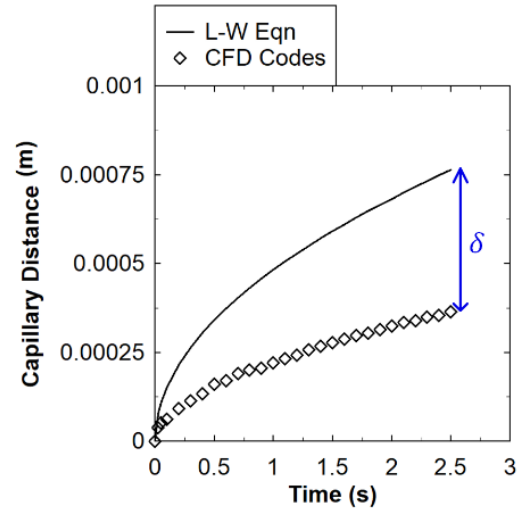

Fig. 6. Evolution of capillary distance with time for each case of CFD simulation with comparison to the theoretical prediction. The deviation in the observed result is also highlighted.

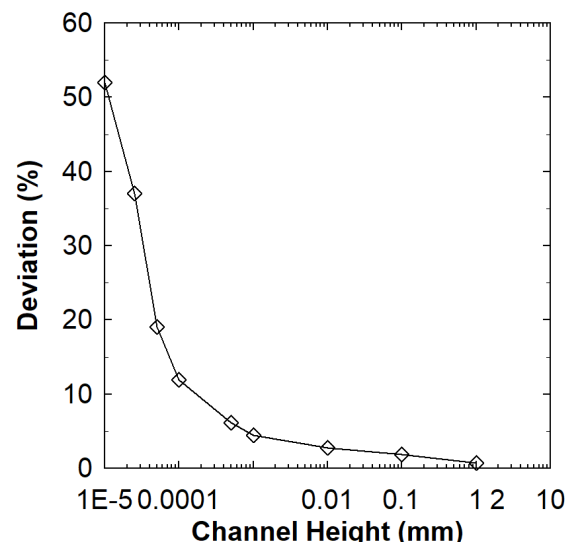

Channel Height $(\mathrm{mm})$

Fig. 7. Variation of deviation percentage in the numerical estimation of capillary length with channel height

\section{CONCLUSION}

In this paper, we perform the capillary flow simulation using CFD inside channels of different geometry. Based on the comparison of results with the analytical solution, it is observed that the deviation at a very small height is significantly large. This establishes that the results from continuum simulations may not be $100 \%$ correct at that scale.

\section{REFERENCES}

[1] Aziz, M. A., Abdullah, M. Z., Khor, C. Y., Jalar, A., \& Ani, F. C. (2014). CFD modeling of pin shape effects on capillary flow during wave soldering. International Journal of Heat and Mass Transfer, 72, 400-410. 
[2] Taha, T., \& Cui, Z. F. (2006). CFD modelling of slug flow inside square capillaries. Chemical Engineering Science, 61(2), 665-675.

[3] Silva, G., Leal, N., \& Semiao, V. (2010). Critical pressure for capillary valves in a Lab-on-a-Disk: CFD and flow visualization. Computers \& structures, 88(23-24), 1300-1309.

[4] Jayakumar, J. S., Mahajani, S. M., Mandal, J. C., Vijayan, P. K., \& Bhoi, R. (2008). Experimental and CFD estimation of heat transfer in helically coiled heat exchangers. Chemical engineering research and design, 86(3), 221-232.

[5] Alizadehdakhel, A., Rahimi, M., \& Alsairafi, A. A. (2010). CFD modeling of flow and heat transfer in a thermosyphon. International Communications in Heat and Mass Transfer, 37(3), 312-318.

[6] Deb, D., Poudel, S., \& Chakrabarti, A. (2017). Numerical Simulation of Hydromagnetic Convection in a Lid-driven Cavity Containing a Heat Conducting Elliptical Obstacle with Joule Heating. International Journal of Engineering Research and Technology, 6(08).

[7] Yadav, A. S., \& Bhagoria, J. L. (2013). Heat transfer and fluid flow analysis of solar air heater: A review of CFD approach. Renewable and Sustainable Energy Reviews, 23, 60-79.

[8] Ghale, Z. Y., Haghshenasfard, M., \& Esfahany, M. N. (2015). Investigation of nanofluids heat transfer in a ribbed microchannel heat sink using single-phase and multiphase CFD models. International Communications in Heat and Mass Transfer, 68, 122-129.

[9] Banerjee, R. (2007). A numerical study of combined heat and mass transfer in an inclined channel using the VOF multiphase model. Numerical Heat Transfer, Part A: Applications, 52(2), $163-$ 183.

[10] Li, H., Vasquez, S. A., \& Spicka, P. (2010, January). Advanced computational modeling of multiphase boiling flow and heat transfer. In ASME International Mechanical Engineering Congress and Exposition (Vol. 44441, pp. 1681-1692).

[11] Li, H., Vasquez, S. A., Punekar, H., \& Muralikrishnan, R. (2011, January). Prediction of boiling and critical heat flux using an eulerian multiphase boiling model. In ASME International Mechanical Engineering Congress and Exposition (Vol. 54921, pp. 463-476).

[12] Zou, A., Poudel, S., Raut, S. P., \& Maroo, S. C. (2019). Pool boiling coupled with nanoscale evaporation using buried nanochannels. Langmuir, 35(39), 12689-12693.

[13] Bastakoti, D., Zhang, H., Li, D., Cai, W., \& Li, F. (2018). An overview on the developing trend of pulsating heat pipe and its performance. Applied Thermal Engineering, 141, 305-332.

[14] Moraveji, M. K., \& Ardehali, R. M. (2013). CFD modeling (comparing single and two-phase approaches) on thermal performance of $\mathrm{Al} 2 \mathrm{O} 3$ /water nanofluid in mini-channel heat sink. International Communications in Heat and Mass Transfer, 44, 157-164.

[15] Moraveji, M. K., Ardehali, R. M., \& Ijam, A. (2013). CFD investigation of nanofluid effects (cooling performance and pressure drop) in mini-channel heat sink. International Communications in Heat and Mass Transfer, 40, 58-66.

[16] Chien, N. B., Choi, K. I., \& Oh, J. T. (2015). Experiment and CFD simulation of boiling heat transfer coefficient of R410A in minichannels. International Journal of Air-Conditioning and Refrigeration, 23(04), 1550032.

[17] Minqiang, P. A. N., Dehuai, Z., Yong, T., \& Dongqing, C. (2009) CFD-based study of velocity distribution among multiple parallel microchannels. J. Comput, 4(11), 1133-1138.

[18] Lan, W., Li, S., Wang, Y., \& Luo, G. (2014). CFD simulation of droplet formation in microchannels by a modified level set method. Industrial \& Engineering Chemistry Research, 53(12), 4913 4921.

[19] Zhang, R., Ikoma, Y., \& Motooka, T. (2010). Negative capillarypressure-induced cavitation probability in nanochannels. Nanotechnology, 21(10), 105706.

[20] Sun, J., He, Y. L., Tao, W. Q., Rose, J. W., \& Wang, H. S. (2012). Multi-scale study of liquid flow in micro/nanochannels: effects of surface wettability and topology. Microfluidics and nanofluidics, 12(6), 991-1008.

[21] Poudel, S., Zou, A., \& Maroo, S. C. (2019). Wicking in CrossConnected Buried Nanochannels. The Journal of Physical Chemistry C, 123(38), 23529-23534.

[22] Poudel, S., Zou, A., \& Maroo, S. C. (2020). Evaporation Dynamics in Buried Nanochannels with Micropores. Langmuir, 36(27), 78017807. DOI: 10.1021/acs.langmuir.0c00777

[23] Vangelooven, J., Malsche, W. D., Detobel, F., Gardeniers, H., \& Desmet, G. (2009). High- Speed Shear-Driven Flows Through Microstructured 1D-Nanochannels. Analytical chemistry, 81(3), 943 952.

[24] Fluent, A. N. S. Y. S. (2015). Ansys fluent. Academic Research. Release, 14.

[25] Washburn, E. W. (1921). The dynamics of capillary flow. Physical review, $17(3), 273$.

[26] Lucas, R. (1918). Rate of capillary ascension of liquids. Kolloid $Z, 23(15), 15-22$

[27] Chengara, A., Nikolov, A. D., Wasan, D. T., Trokhymchuk, A., \& Henderson, D. (2004). Spreading of nanofluids driven by the structural disjoining pressure gradient. Journal of colloid and interface science, 280(1), 192-201.

[28] Bergeron, V., \& Radke, C. J. (1992). Equilibrium measurements of oscillatory disjoining pressures in aqueous foam films. Langmuir, 8(12), 3020-3026.

[29] Klass, D. L., \& Martinek, T. W. (1967). Electroviscous fluids. I. Rheological properties. Journal of Applied physics, 38(1), 67-74.

[30] Geun Kim, B., Sik Lee, J., Han, M., \& Park, S. (2006). A molecular dynamics study on stability and thermophysical properties of nanoscale liquid threads. Nanoscale and microscale thermophysical engineering, 10(3), 283-304. 